\title{
THE COSTS OF WORK-ADDICTED MANAGERS IN ORGANIZATIONS: TOWARDS INTEGRATING GLINICAL AND ORGANIZATIONAL FRAMEWORKS
}

\author{
Pawel A. Atroszko ${ }^{1 *}$ and Bartosz Atroszko ${ }^{2}$ \\ ${ }^{1), 2)}$ University of Gdańsk, Gdańsk, Poland
}

\begin{abstract}
Please cite this article as:
Atroszko, P.A. and Atroszko, B., 2020. The Costs of Work-Addicted Managers in Organizations: Towards Integrating Clinical and Organizational Frameworks. Amfiteatru Economic, 22(Special Issue No. 14), pp. 1265-1282.
\end{abstract}

Article History

Received: 20 May 2020

Revised: 4 August 2020

Accepted: 12 September 2020

\begin{abstract}
Recently some general agreements have been achieved regarding the current status of work addiction. One of the key criteria for conceptualizing a behavioral addiction is the harm caused by the behavior. It has been argued that in the case of work addiction, special attention should be devoted to the potential harm that the behavior causes for the recipients of the work or coworkers. This paper constitutes a narrative literature review of the literature suggesting an association between work addiction of a manager and harm caused to other employees and recipients of their work. Based on this review, it can be concluded that the existing data provide strong premises suggesting that work-addicted managers may cause significant harm to themselves, other employees, organizations, and recipients of their work. It includes potential indirect effects through creating an environment conducive to work addiction and its consequences among employees. However, there are very few studies directly investigating the harm and costs caused by work-addicted managers. This paper constitutes an attempt to integrate certain aspects of clinical and organizational research into work addiction and stimulate further integrations in this area.
\end{abstract}

Keywords: behavioral addiction; health; leadership; work addiction; workaholism

JEL Classification: I12, I18, I80

\footnotetext{
* Corresponding author, Pawel A. Atroszko - e-mail: p.atroszko@ug.edu.pl
} 


\section{Recent developments in the work addiction field}

The current dynamic changes in the official classifications of diseases and disorders include recognition of the category of behavioral addictions (American Psychiatric Association, 2013). These developments, together with a significantly growing body of research concerning work addiction, gave rise to a recent unprecedented debate on the current status of this problematic behavior. It resulted in consensuses among leading experts in the field of work addiction, foremostly representing clinical orientation and addiction expertise (Andreassen, Schaufeli and Pallesen, 2018; Griffiths, Demetrovics and Atroszko, 2018; Kun, 2018; Lior, Abira and Weinstein, 2018; Loscalzo and Giannini, 2018; Malinowska, 2018; Quinones, 2018; Sussman, 2018; Tóth-Király, Bőthe and Orosz, 2018; Atroszko, Demetrovics and Griffiths, 2019). All of the experts recognized compulsive overworking as a genuine problem, and there was general agreement that there was sufficient empirical data to substantiate its relationship with the harm of clinical relevance in terms of physical and mental health problems, sleep disturbance, lower quality of life, and problematic family and social functioning, including potential mental health problems among children of work addicts. Furthermore, it was agreed that for a minority of individuals, it is not a transient behavioral pattern but persists for a significant time, and can be progressive in nature. A general definition of work addiction, understood as a behavioral addiction, was suggested along these lines.

"Work addiction is characterized by a compulsion to work and preoccupation with work activities leading to significant harm and distress of a functionally impairing nature to the individual and/or other significantly relevant relationships (friends, family). The behavior is characterized by the loss of control over the working activity and persists over a significant period of time. This problematic work-related behavior can have varying intensity from mild to severe" (Atroszko, Demetrovics and Griffiths, 2019, p. 9).

This definition is consistent with the existing conceptualizations of work addiction/workaholism in the organizational literature which include the elements of preoccupation with work/compulsion or addiction to work, and negative consequences of excessive work (Fassel, 1992; Spence and Robbins, 1992; Schaufeli, Taris and Bakker, 2006). The nature and diagnostic approach to particular symptoms were discussed (Atroszko, Demetrovics and Griffiths, 2019). On the example of medical errors, it was emphasized that the symptom of work addiction related to work activities leading to significant harm and distress of a functionally impairing nature should include the recipients of the work. In this context, a specific case of this symptom is the impact of work-addicted managers on the employees.

Available data suggest that around $10 \%$ of the working population across industrialized countries might be at risk of work addiction (Sussman, Lisha, \& Griffiths, 2011); however, the estimates depend upon the instrument used and particular country (Griffiths, Demetrovics and Atroszko, 2018). The most theoretically substantiated and empirically validated polythetic cut-off (consistent with modern nosologies) is based on the Bergen Work Addiction Scale (BWAS). Studies using this method showed prevalence rates ranging from 6.6\% in Denmark (Lichtenstein, et al., 2019), 8.1\% among Swiss men (Marmet, et al., 2019), 8.3\% in a nationally representative sample in Norway (Andreassen, et al., 2014), to as high as $17.4 \%$ in Poland (Atroszko, et al., 2017) or $20.6 \%$ in Hungary (Orosz, et al., 2016; Griffiths, Demetrovicz and Atroszko, 2018). These estimates are nontrivial and significantly higher than most of the other addictions (Sussman, Lisha and 
Griffiths, 2011). There was general agreement that work addiction is not purely personality problem, and more research on the contribution of meso-level and macro-level factors to work addiction is warranted (Atroszko, Demetrovics and Griffiths, 2020).

Moreover, a pending need to integrate the relatively extensive body of research within work and organizational framework with the clinical framework, and more transdisciplinary approach to the research was expressed (Lior, Abira and Weinstein, 2018; Quinones, 2018; Tóth-Király, Böthe and Orosz, 2018; Atroszko, 2019a). There are still very few efforts to integrate different theoretical and empirical approaches to work addiction (Andreassen and Pallesen, 2016; Andreassen, et al., 2017; Shkoler, et al., 2017; Griffiths, Demetrovics and Atroszko, 2018; Atroszko, 2019). This problematic behavior is a highly transdisciplinary phenomenon, and as such, requires networks of integrated collaborations between experts from diverse fields to systematically and incrementally develop a body of knowledge based on consensuses. This paper constitutes a narrative literature review (Grant and Booth, 2009) examining papers on a particular issue concerning work addiction within the organizational context, that is, the harm and the costs generated by work addicted managers. As such, it constitutes an effort to provide initial integration of certain aspects of research from clinical and organizational literature. Since more clinically oriented researchers prepared this review, it does not aspire to be exhaustive and rather constitutes a plea for more systematic integrations by experts from work and organization psychology, as well as management. For example, previously, some efforts were undertaken at theoretically analyzing how workaholism may affect the functions and responsibilities of a leader. They included formulating the implications of the workaholism of leaders for their own and their followers' well-being within the context of organizational psychology (Clark, Stevens, Michel and Zimmerman, 2016). Potential cross-over effects between leaders and followers were identified. The current review analyzes probable specific mechanisms of such crossover effects in the light of the recent developments in the literature on work addiction, especially from the perspective of behavioral addiction framework and clinical psychology.

The present paper is also an extension of a recent article analyzing the role of work addiction in burn-out and the global burden of disease, which suggested a model including micro-, meso- and macro-level factors contributing to compulsive overworking (Atroszko, Demetrovics and Griffiths, 2020). Within this model (figure 1 in the paper by Atroszko et al., 2020), and congruent with the model suggested by Clark, Stevens, et al. (2016), managers have a dual function. First, they may develop work addiction as a result of the interplay of the identified risk factors (individual vulnerabilities such as rigid perfectionism, the culture of competition and hostility, and organizational factors such as overworking climate and job demands). Second, managers may also be responsible for creating risk factors via excessive job demands and non-optimal management behaviors contributing to the overworking climate. Therefore, they could be identified as meso-level factors in the model. Consequently, in the current review paper, two sources of harm from work-addicted managers are considered: i) direct harm in terms of employee stress and problematic management and their consequences, including loss of productivity by the organization, ii) indirect harm via creating an environment conducive to employee work addiction and its consequences.

The role of organizational climate on employee work addiction-related behaviors and attitudes has been described and investigated since the late 1980s with such notable examples as works of Killinger (1992), and Schaef and Fassel's (1988) idea of "addictive

Vol. 22 • Special Issue No. $14 \cdot$ November 2020 
organizations." In these early years of identifying those who are driven to spend long hours at work, the term 'workaholic' was not always used to indicate strictly negative phenomenon (Machlowitz, 1980). This ambiguity, however, was clarified in recent decades. Papers in defense of workaholism presenting it as a positive phenomenon appear incidentally (Baruch, 2011); however, currently, there is an unambiguous agreement among leading experts in the field that work addiction/workaholism is a negative phenomenon (see Griffiths, Demetrovics and Atroszko, 2018; Atroszko, Demetrovics and Griffiths, 2019). The role of peer-pressure and work ethos is perhaps most pronounced in the case of medical doctors who often self-identify as being forced to be work addicts. This phenomenon was mentioned in the medical literature since the 1970s, with an interesting series of papers in the Canadian medical journals from that period (Vincent, 1976; Henry, 1979; Cohen, 1980) and an article in British Medical Journal (Hey, 1994). Currently, the consequences of high pressure to work hard among health care professionals (HCP) are reflected in the epidemic of burn-out in these professions across industrialized countries (Imo, 2017; Panagioti, Panagopoulou, Bower, et al., 2017). Interestingly, presenteeism (attending work while ill) is a widespread phenomenon among $\mathrm{HCP}$, and the most frequently reported reasons for presenteeism among residents are an obligation to colleagues and an obligation to patient care (Jena, et al., 2012). It was suggested that organizational culture has a significant impact on an individual's work addiction (Burke, 2001; Johnstone and Johnston, 2005; Fry and Cohen, 2009). An increasing number of studies confirm that (Andreassen, et al., 2017; Andreassen, Pallesen and Torsheim, 2018; Avanzi, et al., 2012; Mazzetti, Schaufeli and Guglielmi, 2014), including data showing that work addiction mediates between work stressors and health (Andreassen, et al., 2018). It is consistent with observations from epidemiology, which show that there is a direct relationship between the average level of behavior in population and the prevalence of particular diseases or disorders related to that behavior (Rose, 2001). For example, knowing the mean level of alcohol consumption in the population, we can reasonably precisely predict the number of problematic alcohol users, including those fulfilling criteria for alcohol use disorder.

A highly competitive culture and focus on narrowly defined productivity (e.g., within academia, this could mean output in terms of the number of papers and research projects instead of quality and meaning of research) affecting the working environment are important macro-level factors which may be contributing to work addiction of employees.

It was recently highlighted that their impact on vulnerable individuals might be often mediated by the role of the meso-level organizational factors such as management styles and behaviors (Atroszko, Demetrovics and Griffiths, 2020). Organization leaders are the individuals responsible for the organizational culture and climate, and studies clearly show the managers' impact on employees' well-being (Robertson and Flint- Taylor, 2009; Clark, Stevens, et al. 2016). Of course, macro-level factors such as extremely competitive markets and governmental policies have their influence on the way organizations operate. However, it can be argued that these macro-level factors are not entirely responsible for particular management choices in individual organizations, and organizational identification plays a noteworthy role in personal attitudes and behaviors of employees in organizations (Lee, Park and Koo, 2015). Work addiction has been consistently linked to high job demands (Balducci, et al., 2015; Clark, Michel, et al., 2016), including in longitudinal studies (Balducci, Avanzi and Fraccaroli, 2018). These results suggest that high demands increase work addiction. The role of job demands in relation to work addiction should be carefully 
investigated in longitudinal studies as well as perhaps experimental settings as some crosssectional models and studies suggest that job demands may be a consequence of work addiction (Guglielmi, et al., 2012).

Possible feedback loops (e.g., work addiction may increase work-role conflict, and this, in turn, may increase work addiction) can explain such results and are theoretically feasible; therefore, this issue requires more in-depth analysis. The close relationship between job demands and compulsive overworking is congruent with a model in which work addiction is a result of ineffective coping with other underlying problems and stress (Atroszko, 2019; Atroszko, Demetrovics and Griffiths, 2019; Molino, Bakker and Ghislieri, 2016). Higher pressure and strain in the work environment (understood as job demands and problematic management practices, and their consequences) may result in vulnerable individuals increasing their work effort and, in consequence, exacerbating their work addiction. Susceptible individuals are especially those showing rigid perfectionism and anankastia/obsessive-compulsive personality disorder (OCPD); (Atroszko, Demetrovics and Griffiths, 2020) who do not implement effective coping strategies, such as, for example, seeking social support or reappraising situation.

At the same time, it is necessary to remember that the environmental factors may have a more limited role in the cases of individuals highly predisposed to addiction (Sussman, 2012), such as those showing the symptoms of anankastia/OCPD; (Atroszko, 2019a,b). For this reason, in a certain way, individual vulnerabilities (like rigid perfectionism) are likely to be the most important risk factor for this addiction and the one responsible for the persistence of the disorder in the case of a minority of individuals (Atroszko, Demetrovics and Griffiths, 2020). This may seem an ambiguous assumption since, in a recent debate, it was agreed that work addiction is not purely a personality problem (Atroszko, Demetrovics and Griffiths, 2019), and macro-level factors have an arguably substantial effect on compulsive overworking (Atroszko, Demetrovics and Griffiths, 2020). However, in the light of the current understanding of addiction, it is an entirely consistent argument, though nuanced, and perhaps requires elaboration here.

Both substance use disorders and behavioral addictions are highly sensitive to environmental factors. In particularly adverse and stressful circumstances, like during war or while living in underprivileged conditions and chaotic environments (Caprioli, et al., 2007; Sinha, 2009; Satel and Lilienfeld, 2013), a considerable portion of the population may show symptoms of substance-related or behavioral addiction (consistent with Rose's theorem; Rose, 2001). Moreover, in such circumstances, many affected individuals may suffer the most severe consequences of addiction like death due to overdose, suicide or health complications (Baker, 1971; Bentel and Smith, 1971). At the same time, changing the environment may result in a dramatic decrease in the number of individuals affected by addiction (Caprioli, et al., 2007; Sinha, 2009; Satel and Lilienfeld, 2013). However, it does not reduce the risks entirely as there will remain a minority of individuals affected by disordered behavior. In these cases, individual vulnerabilities like other underlying mental problems, persistent neural changes, or other unrecognized environmental factors may be critical for maintaining the behavior (Caprioli, et al., 2007). For these reasons, it was argued that the presence of other disorders should not be an exclusion criterium for diagnosing work addiction (Atroszko, 2019). In the cases of work addicts, rigid perfectionism and anankastia/OCPD may be specific risk factors related to individual vulnerabilities. At the same time, extremely demanding managerial styles and 
organizational cultures may create stressful and chaotic environments eliciting work addiction symptoms in a substantial portion of employees. Some may argue that in the latter case, a diagnosis should be precluded since it is a transient behavioral pattern in response to the environment; however, two factors need to be taken into account.

First, if the stress is considerable and/or prolonged, the behavior in response to it may cause long-lasting neural and behavioral changes resulting in persisting addiction among some individuals (Sinha, 2009; Briand and Blendy, 2010). In other words, a disorder may continue even after the eliciting environment has changed. Moreover, even after the change of the environment and decrease in addiction symptoms or full remission, there may be persistent health consequences and long-lasting substantially increased risk for mortality (Price, et al., 2001). The study on Vietnam War veterans showed that this effect was present even after controlling for pre-service drug use, continuity to later drug use, and demographic and other behavioral measures. The magnitude of the direct impact of drug use on mortality was more significant than those of the covariates, except age.

Second, even relatively shorter periods of high work-related stress (months or few years), leading to work addiction, may result in dramatic consequences such as death from overworking or suicide. These extreme outcomes are well-documented and not infrequent (Atroszko, 2019; Atroszko, Demetrovics and Griffiths, 2019). For example, to diagnose a major depressive disorder, the symptoms must be present during the same 2-week period. Such a short period of symptoms' presence allowing official diagnosis is understandable (though in some cases controversial, see, for example, Wakefield and Schmitz, 2013), especially when a disorder may cause dangerous consequences such as suicide. In such cases, the question is not whether the extremely demanding environments may cause overworking to the point of death (e.g., for the discussion of deaths from overworking among Polish and Japanese medical doctors see Atroszko, Demetrovics and Griffiths, 2019). Instead, the issue is how to distinguish these more environmentally caused patterns of overworking, including transient ones (and deciding whether they are related to compulsion), from a rather persistent personality dependent patterns of work addiction? Whether the former case is a real addiction or rather some transient stress-related problematic behavior or disorder is an open question. It pertains to the overall discussion on what addiction in general is (not only work addiction) and how it should be diagnosed (Satel and Lilienfeld, 2013). Because of these interrelationships between different levels of risk factors, it was argued that state policies or meso-level organizational factors might moderate the relationship between individual vulnerabilities and work addiction (Atroszko, Demetrovics, Griffiths, 2020), and that more good quality studies on this issue are highly warranted.

Work addiction is more often investigated from an organizational perspective than the clinical one (Clark, Michel, et al., 2016; Griffiths, et al., 2018; Atroszko, 2019). It shows that it is widely recognized in the organizational settings but not always conceptualized as a clinically relevant problem (Snir, Harpaz and Burke, 2006). Often it is defined as working long hours, typically in the Heavy Work Investment model (Snir and Harpaz, 2006), which can lead to confounding results of studies if substantial work investment is confused with addiction (Atroszko, Demetrovics, Griffiths, 2019). This approach of describing workaholism in terms of high problematic involvement in work rather than a compulsive behavioral pattern of clinical relevance could be related to the reluctance to pathologize everyday behaviors. The benefit of this careful approach could be that it may have allowed 
for relatively common recognition of the behavior in the organizational literature and its investigation without strong resistance that is frequently produced by a clinical approach, oftentimes perceived as stigmatizing. However, with the dynamic changes in the way behavioral addictions are understood and officially recognized as disorders, it seems timely to introduce some aspects of the clinical framework into organizational research and integrate the results from both areas. Notably, work addiction understood as a behavioral addiction assumes a loss of control over the behavior, most frequently related to lack of awareness of the problem or unwillingness to seek help typical for addictions (Atroszko Demetrovics and Griffiths, 2019). In this context, it is crucial to acknowledge that a manager in the organization may have lost control over certain aspects of their involvement in work in a way that may be harmful to employees, organizations, and the recipients of the work. This recognition requires a specific, careful, and sensitive approach to manage the problem, and it seems critical for organizations to develop potential solutions to this problem in cooperation with health professionals. However, to implement them effectively, general and systematic support from international work, and health institutions and proper state policies are highly warranted (Atroszko, Demetrovics and Griffiths, 2020).

Recently, the role of mental health in the workplace is gaining increasing attention with such notable developments as World Health Organization's (WHO) inclusion of a more detailed definition of burn-out (WHO, 2019a) in the 11th Revision of the International Classification of Diseases (ICD-11). Burn-out is reaching a status of an epidemic in specific professions such as medical doctors and other health professionals (Imo, 2017; Panagioti, et al., 2017), and lately in academia among Ph.D. students (Levecque, et al., 2017; Nature, Editorial, 2019). The WHO's Global Plan of Action on Worker's Health (2008-2017) and Mental Health Action Plan (2013-2030) describe relevant principles, objectives, and implementation strategies to promote good mental health in the workplace (WHO, 2019b). Currently, the WHO recognizes a variety of factors that make professional work one of the significant contributors to the global burden of disease (Virtanen, et al., 2012; Bannai and Tamakoshi, 2014). In this context, a particular problem, not addressed explicitly by the WHO, is the role of organizational managers' work addiction as contributing to employee's harm and loss of productivity (Atroszko, Demetrovics and Griffiths, 2020). Especially that there is a direct relationship between the quality of the relationship with the supervisor and employee's burn-out (Zimmerman, 2018).

\section{Work addiction among managers}

Managers are fairly frequently studied in relation to workaholism/work addiction from the organizational perspective, as it is typically assumed that they are at higher risk for such behavioral patterns (Clark, Stevens, et al., 2016). Indeed, the available studies consistently show that managerial positions are related to a higher risk of work addiction (Taris, Van Beek and Schaufeli, 2012; Littman-Ovadia, Balducci and Ben-Moshe, 2014; Atroszko, et al., 2017). A large epidemiological study showed that being a manager is among the most important socio-demographic risk factors for work addiction (Andreassen, et al., 2016). Furthermore, there are several factors concerning managers' characteristics related to work addiction, which strongly suggest that, apart from causing harm for themselves, they may have a significant harmful effect on the well-being of employees and overall productivity of an organization. These individual factors include anankastia/OCPD and rigid perfectionism, Type A personality, narcissism, attention-deficit hyperactivity disorder (ADHD), and 
hypomania/bipolar disorder, which may significantly contribute to stress cross-over effects in work-environment. These are mostly clinically-based constructs that could be integrated with organizationally oriented models (Clark, Stevens, et al., 2016).

Firstly, work addiction is closely related to the anankastia/OCPD and rigid perfectionism (Atroszko, 2019a,b), which may predispose the managers to focus on unimportant details and striving for unrealistic standards. OCPD (Fifth Edition of the Diagnostic and Statistical Manual for Mental Disorders, DSM-5; American Psychiatric Association, 2013) or anankastic personality disorder (APD), is currently recognized by WHO as personality disorder with prominent anankastic features (anankastia; ICD-11 classification; WHO, 2019c). Anankastia in personality disorder or personality difficulty is characterized by WHO in the following manner:

"The core feature of the Anankastia trait domain is a narrow focus on one's rigid standard of perfection and of right and wrong, and on controlling one's own and others' behaviour and controlling situations to ensure conformity to these standards. Common manifestations of Anankastia, not all of which may be present in a given individual at a given time, include: perfectionism (e.g., concern with social rules, obligations, and norms of right and wrong, scrupulous attention to detail, rigid, systematic, day-to-day routines, hyperscheduling and planfulness, emphasis on organization, orderliness, and neatness); and emotional and behavioral constraint (e.g., rigid control over emotional expression, stubbornness and inflexibility, risk-avoidance, perseveration, and deliberativeness)" (WHO, 2019c).

A recent paper (Atroszko, Demetrovics and Griffiths, 2020) drew attention to the relationship between anankastia/OCPD, work addiction, burn-out and the global burden of disease, noting that anankastia in personality disorder or OCPD: i) is the most prevalent personality disorder among the general population $(3 \%-8 \%)$ and outpatient groups, ii) has been identified as producing the highest economic burden among personality disorders in terms of direct medical costs and productivity losses, iii) is strongly related to burn-out, and iv) work addiction. For example, a Finnish study showed that $50 \%$ of men and $28 \%$ of women with first-episode depression among employed individuals recruited from occupational health care units were diagnosed with OCPD (Raiskila, et al., 2013). The scale of this effect may help realize the potential scope of the role of anankastia/OCDP in the workforce's well-being. Depression is among the most common causes of working disability in industrialized countries. The current estimated cost of depression related to stress at work in the European Union is $€ 617$ billion annually, which is higher than any other disease or disorder and more than the gross domestic product (GDP) of most European countries (European Agency for Safety and Health at Work, 2014).

Secondly, work addiction is related to Type A personality components of competitiveness and hurry (Clark, Michel, et al., 2016; Griffiths, et al., 2018; Atroszko and Atroszko, 2019). These may prompt work addicts to create excessive job demands, e.g., undertaking too many projects and tasks, and imposing unrealistic time frameworks to carry them out (Midje, et al., 2014; Clark, Stevens, et al., 2016). Thirdly, work addiction was found to be related to narcissism (Andreassen, et al., 2012; Atroszko, Sawicki and Kamble, 2019). Narcissistic managers and employees tend to be problematic in work settings (Judge, Piccolo and Kosalka, 2009; O'Boyle, et al., 2012). Narcissistic work-addicted managers may have grandiose expectations, and their competitiveness may produce hostile attitudes to coworkers. A study showed a positive indirect effect of employee performance on 
abusive supervision through supervisor envy in the case of supervisors with a high social comparison orientation (Tariq, et al., 2019). Furthermore, work addiction has been consistently related to ADHD (Andreassen et al., 2016; Atroszko, et al., 2017; Marmet, et al., 2019). Inattention and restlessness of a manager may have significant consequences for the employees and the organization. Also, work addiction was found to be related to bipolar disorder and hypomania (Di Nicola, et al., 2010; Marmet, et al., 2019). This comorbidity can have profound consequences for the employees and organization as bipolar disorder is related to reckless and impulsive decision making. Furthermore, it can have a significant, adverse effect on work relationships, attendance, and functioning, which can lead to substantial costs arising from lost productivity (Laxman, Lovibond and Hassan, 2008). The findings in the clinical literature suggest that work addiction, similar to other addictions, including substance-related ones, may be a result of initial behavioral coping mechanisms to deal with some other underlying psychopathology (Atroszko, 2019a,b). Work addiction could be a result of a coping attempt specific for particular disorders such as anankastia/OCPD or ADHD. In such a case, both work addictive patterns and underlying problems should be identified and addressed. To our knowledge, there is a lack of systematic research into ADHD or anankastia/ OCPD among managers and leaders.

One of the key health-related factors in understanding how personal characteristics and managing style of managers may affect employees is to recognize the way work addiction influences sleep patterns and sleep quality. This is related to specific and potentially critical cross-over and spill-over effects involving managers' poor sleep quality affecting their behavior and, in turn, affecting stress levels, sleep quality, and the behavior of employees. Sleep is fundamental to psychological and physical well-being, as well as productivity, and is strictly related to health and mortality (Gallicchio and Kalesan, 2009). Work addiction is negatively associated with sleep quality (Griffiths, et al., 2018). Recently, there is a rapidly increasing number of studies aiming to explain the mechanisms by which work addiction affects sleep disturbance (Gillet, et al., 2018; Spagnoli, et al., 2018; Hancock, et al., 2019; Reiner, et al., 2019; Scafuri Kovalchuk, et al., 2019; Spagnoli, et al., 2019). An experience sampling study showed that supervisors' sleep problems are related to employees' sleep problems (Tariq, et al., 20182019). This study found a spill-over effect of supervisors' poor sleep on their next- day abusive supervisory behavior, which in turn had a cross-over effect on their subordinates' poor sleep. It is consistent with the findings that work addiction is related to negative affect at work, and this, in turn, is related to anxiety before sleep (Spagnoli, et al., 2018).

Moreover, work addiction was found to be related to aggressive behavior at work (Balducci, et al., 2012). Taking into account that the managers' behavior is likely to affect the largest number of employees, their propensity to sleep problems, negative affect, and aggression at work may have a significant effect on other workers. Both managers and employees may perform their work not only while sleep-deprived, which will likely affect their performance, but also when they are patently ill, including suffering from contagious infections. In such cases, they pose an additional threat to the health of employees and other people while commuting to work or performing their work. A factor that perhaps has never in recent decades been more critical than currently amidst global COVID 19 pandemic.

There is a growing interest in the phenomenon of presenteeism in the workplace, which refers to attending work while ill (Johns, 2010). This phenomenon is related to productivity loss and currently poses a serious epidemiological threat in the COVID-19 pandemic 
(Eisen, 2020). This has enormous significance since studies show that presenteeism is widespread among HCP (Jena, et al., 2010), and more than $40 \%$ of HCP with influenza-like illness work while ill during the influenza season (Chiu, et al., 2017). A longitudinal study showed a positive relationship between presenteeism and burn-out (Demerouti, et al., 2009). There is an association of perfectionism and work addiction with presenteeism among managers (Girardi, et al., 2015). Presenteeism mediates the association between workaholism and work-family conflict, and this relationship is moderated by managerial support (Mazzetti, et al., 2019). Work addiction is more strongly related to presenteeism for the employees reporting lower levels of support than for those experiencing higher support. These studies suggest that through manifesting, accepting and promoting presenteeism at work, work-addicted managers may contribute to higher risks of burn-out and other health problems, as well as related productivity loss among employees. More systematic studies are clearly needed on this issue.

One area of research that is under-represented in the work addiction literature is related to the studies on the highest-level managers and leaders because they are typically most difficult to reach. If they cannot be reached, observer ratings could be used as an indicator of their work addiction-related attitudes and behaviors. Studies show reasonably high congruence of self-reports and observer ratings in terms of measuring work addiction; however, it should be taken into account that the rater agreement is typically higher for such components as working excessively rather than working compulsively (Falco, et al., 2012; Littman-Ovadia, et al., 2014; Mazzetti, Schaufeli and Guglielmi, 2018).

\section{Conclusions and suggestions for future research}

The current literature review allows for drawing several noteworthy conclusions. First, holding a managerial position is one of the most important socio-demographic risk factors for work addiction. Second, organizational leaders have a direct impact on employee wellbeing and are responsible for the organizational culture and climate. Thirdly, since these are recognized factors contributing to work addiction, managers may be an essential source of work addiction and its consequences in organizations.

The crucial question is to what extent work-addicted managers may be a risk factor for work addiction among employees and to what extent their impact is limited to other forms of harm to employees, organizations, and recipients of work? The existing data suggest a substantial contribution of work-addicted managers to the harm of employees in terms of chronic stress, mental and physical illness, and loss of productivity due to inefficient management. Work addiction of a leader may be one of the critical factors thwarting the potential of employees to thrive in their work roles and creating unnecessary costs for the organization. Work addicted managers may create a climate of overworking, which may have profound consequences when the role of the environment in addiction is considered. These consequences are probably most pronounced if the adverse and stressful environmental circumstances last for a long time.

However, based on studies in substance use disorders and some of the research into work addiction, it can be expected that a highly stressful environment and overworking climate, even if relatively transient, may: i) elicit addiction symptoms in vulnerable individuals, ii) directly and indirectly contribute to extreme consequences of overworking and compulsive overworking such as death from overwork or health complications, as well as suicide, iii) 
directly and indirectly contribute to other consequences of overworking and compulsive overworking, such as health problems and their complications, family problems, and loss of productivity, iv) trigger long-lasting addictive pattern in vulnerable individuals, which may persist even after a change of environment, v) cause long-term health consequences of overworking and compulsive overworking even after a change of environment and resolution of addiction symptoms.

This brief review suggests a great need to systematically integrate the existing data on leadership behavior and its role in employees' well-being in the context of work addiction. It points to a pending need for more systematic good quality studies directly investigating the potential harm caused by work-addicted managers. These challenges require expertise in work and organizational psychology as well as related fields such as management, and collaboration with clinical psychologists and health experts. The analysis of the gaps in our knowledge on this issue indicates several crucial areas for future research: i) estimation of the prevalence rates of work addiction among leaders (especially at highest managerial positions); in order to provide comparable estimates and integrate results it is recommended to use short, clinically based and validated tools such as BWAS alongside Dutch Work Addiction Scale (DUWAS) typically used in organizational settings, ii) the direct and indirect impact of work-addicted managers on employees' health and well-being, as well as the impact on their productivity, including harm caused to recipients of the work, e.g., harm caused by medical errors in health facilities managed by work-addicted individuals, iii) estimation of the social and economic costs of work-addicted managers, iv) the role of work addiction and leadership in Job Demands-Resources Model needs further in-depth analysis and clarification, especially with longitudinal and experimental data, v) integrations and studies concerning relationship of work addiction and leadership with presenteeism, workplace bullying, leadership styles and destructive leadership, workplace deviance, organizational culture, and absenteeism (for example, in order to avoid working in a highly stressful environment) are highly warranted, vi) uncovering factors fostering and mechanisms behind selecting work addicted leaders (for example, focusing solely on superficial self-confidence or agentic qualities, instead of emotional stability and reliance, or relational qualities and high emotional intelligence).

Furthermore, this review focused on the functioning of managers within the context of an organization; however, substantial spill-over and cross-over effects to family functioning of work addicts were previously found and constitute an extension of harm into family and social life (Clark, Stevens, et al., 2016; Clark, Michel, et al., 2016). This issue requires particular attention and separate in-depth analyses. In many cases, these areas would benefit from systematic reviews and meta-analyses of the available research. While there are very few direct studies on the harms and costs of work-addicted managers, there is already a plethora of indirect data on certain aspects of the problem which awaits systematic integrations, for example, extensive and still growing presenteeism literature.

Finally, the question is, how do we choose leaders? In the context of culture valuing competitiveness and busyness, the mechanisms behind identifying and promoting leaders may be overwhelmingly focused on those who work hard and are driven by competition. But do we really need aggressive and busy managers or rather wise and productive leaders? The global epidemic of burn-out and its enormous social and economic costs seem to indicate a high need to switch from workaholic and hectic management to wise, balanced, and health-promoting leadership.

Vol. $22 \cdot$ Special Issue No. $14 \cdot$ November 2020 


\section{References}

American Psychiatric Association, 2013. Diagnostic and statistical manual of mental disorders, 5th ed. Arlington, VA: American Psychiatric Publishing.

Andreassen, C.S., Bakker, A.B., Bjorvatn, B., Moen, B.E., Magerøy, N., Shimazu, A., Hetland, J. and Pallesen, S., 2017. Working conditions and individual differences are weakly associated with workaholism: A 2-3-year prospective study of shift-working nurses. Frontiers in Psychology, 8, p.2045. doi: 10.3389/fpsyg.2017.02045.

Andreassen, C.S., Griffiths, M.D., Hetland, J., Kravina, L., Jensen, F. and Pallesen, S., 2014. The prevalence of workaholism: A survey study in a nationally representative sample of Norwegian employees. Plos One, 9(8), p.e102446. https://doi.org/ 10.1371/journal.pone.0102446.

Andreassen, C.S., Griffiths, M.D., Sinha, R., Hetland, J. and Pallesen, S., 2016. The relationships between workaholism and symptoms of psychiatric disorders: A large-scale cross-sectional study. Plos One, 11(5), p.e0152978.

Andreassen, C.S. and Pallesen, S., 2016. Workaholism: An addiction to work. In: V.R. Preedy (Ed.). Neuropathology of drug addictions and substance misuse. London: Academic Press. pp.972-983.

Andreassen, C., Pallesen, S. and Torsheim, T., 2018. Workaholism as a mediator between work-related stressors and health outcomes. International Journal of Environmental Research and Public Health, 15(1), p.73. DOI: 10.3390/ijerph15010073.

Andreassen, C.S., Schaufeli, W.B. and Pallesen, S., 2018. Myths about "The myths about work addiction": Commentary on: Ten myths about work addiction (Griffiths et al., 2018). Journal of Behavioral Addictions, 7(4), pp.858-862. DOI: 10.1556/ 2006.7.2018.126.

Andreassen, C.S., Ursin, H., Eriksen, H.R. and Pallesen, S., 2012. The relationship of narcissism with workaholism, work engagement, and professional position. Social Behavior and Personality: an International Journal, 40(6), pp.881-890. DOI: https://doi.org/10.2224/sbp.2012.40.6.881.

Atroszko, P.A., 2019a. Work addiction as a behavioural addiction: Towards a valid identification of problematic behavior. The Australian and New Zealand Journal of Psychiatry, 53(4), pp.284-285.

Atroszko, P.A., 2019b. Response to: Loscalzo and Giannini (2018). A boon of incoherence: Insights on the relationship between study/work addiction and obsessive-compulsive personality disorder. Psychiatria i Psychologia Kliniczna, 19(2), pp.237-243. DOI: 10.15557/PiPK.2019.0025.

Atroszko, P.A. and Atroszko, B., 2019. Type-A personality competitiveness component linked to increased cardiovascular risk is positively related to study addiction but not to study engagement. Current Science, 117(7), pp.1184-1188.

Atroszko, P.A., Demetrovics, Z. and Griffiths, M.D., 2019. Beyond the myths about work addiction: Toward a consensus on definition and trajectories for future studies on problematic overworking. A response to the commentaries on: Ten myths about work addiction (Griffiths et al., 2018). Journal of Behavioral Addictions, 8(1), pp.7-15.

Atroszko, P.A., Demetrovics, Z. and Griffiths, M.D., 2020. Work addiction, obsessivecompulsive personality disorder, burn-out, and global burden of disease: Implications 
from the ICD-11. International Journal of Environmental Research and Public Health, 17(2), p.660.

Atroszko, P.A., Pallesen, S., Griffiths, M.D. and Andreassen, C.S., 2017. Work addiction in Poland: Adaptation of the Bergen Work Addiction Scale and relationship with psychopathology. Health Psychology Report, 5(4), pp.345-355.

Atroszko, P.A., Sawicki, A. and Kamble, S., 2019. Cross-cultural pilot study on the relationship between study addiction and narcissism among undergraduate students in Poland and India. Health Psychology Report, [online] Available at: <https://www.termedia.pl/doi/10.5114/hpr.2019.88058> [Accessed 25 June 2020].

Avanzi, L., van Dick, R., Fraccaroli, F. and Sarchielli, G., 2012. The downside of organizational identification: Relations between identification, workaholism and wellbeing. Work \& Stress, 26(3), pp.289-307.

Balducci, C., Avanzi, L., Consiglio, C., Fraccaroli, F. and Schaufeli, W., 2015. A crossnational study on the psychometric quality of the Italian version of the Dutch Work Addiction Scale (DUWAS). European Journal of Psychological Assessment, 33(6), pp.422-428. DOI: 10.1027/1015-5759/a000300.

Balducci, C., Avanzi, L. and Fraccaroli, F., 2018. The individual "costs" of workaholism: An analysis based on multisource and prospective data. Journal of Management, 44(7), pp.2961-2986.

Balducci, C., Cecchin, M., Fraccaroli, F. and Schaufeli, W.B., 2012. Exploring the relationship between workaholism and workplace aggressive behaviour: The role of job-related emotion. Personality and Individual Differences, 53(5), pp.629-634.

Baker, J.S., 1971. Drug abuse in the United States Army. Bulletin of the New York Academy of Medicine, 47(6), pp.541-549.

Bannai, A. and Tamakoshi, A., 2014. The association between long working hours and health: A systematic review of epidemiological evidence. Scandinavian Journal of Work, Environment \& Health, 40, pp.5-18.

Baruch, Y., 2011. The positive well-being aspects of workaholism in cross cultural perspective. Career Development International, 16(6), p.572.

Bentel, D.J. and Smith, D.E., 1971. Drug abuse in combat: The crisis of drugs and addiction among American troops in Vietnam. Journal of Psychedelic Drugs, 4(1), pp.23-30.

Briand, L.A. and Blendy, J.A., 2010. Molecular and genetic substrates linking stress and addiction. Brain Research, 1314, pp.219-234.

Burke, R.J., 2001. Workaholism in organizations: The role of organizational values. Personnel Review, 30(6), pp.637-645.

Caprioli, D., Celentano, M., Paolone, G. and Badiani, A., 2007. Modelling the role of environment in addiction. Progress in Neuro-Psychopharmacology \& Biological Psychiatry, 31(8), pp.1639-1653.

Chiu, S., Black, C.L., Yue, X., Greby, S.M., Laney, A.S., Campbell, A.P. and de Perio, M.A., 2017. Working with influenza-like illness: Presenteeism among US health care personnel during the 2014-2015 influenza season. American Journal of Infection Control, 45(11), pp.1254-1258. 
Clark, M.A., Michel, J.S., Zhdanova, L., Pui, S.Y. and Baltes, B.B., 2016. All work and no play? A meta-analytic examination of the correlates and outcomes of workaholism. Journal of Management, 42(7), pp.1836-1873. https://doi.org/10.1177/0149206 314522301.

Clark, M.A., Stevens, G.W., Michel, J.S. and Zimmerman, L., 2016. Workaholism among leaders: Implications for their own and their followers' well-being. In: W.A. Gentry, C. Clerkin, P.L Perrewé, J.R.B. Halbesleben and C.C. Rosen (Eds.). Research in occupational stress and well-being. [online] Emerald Group Publishing Limited. pp.1-31. Available at: <https://www.emerald.com/insight/content/doi/10.1108/S1479355520160000014001/full/html> [Accessed 5 June 2020].

Cohen, S., 1980. The conspiracy of silence. Canadian Family Physician, 26, pp.847-849.

Demerouti, E., Le Blanc, P.M., Bakker, A.B., Schaufeli, W.B. and Hox, J., 2009. Present but sick: A three-wave study on job demands, presenteeism and burn-out. Career Development International, 14(1), pp.50-68.

Di Nicola, M., Tedeschi, D., Mazza, M., Martinotti, G., Harnic, D., Catalano, V., Bruschi, A., Pozzi, G., Bria, P. and Janiri, L., 2010. Behavioural addictions in bipolar disorder patients: Role of impulsivity and personality dimensions. Journal of Affective Disorders, 125(1-3), pp.82-88.

Eisen, D., 2020. Employee presenteeism and occupational acquisition of COVID-19. The Medical Journal of Australia, [online] Available at: <https://www.mja.com.au/journal/ 2020/employee-presenteeism-and-occupational-acquisition-covid-19> [Accessed 15 March 2020].

European Agency for Safety and Health at Work, 2014. Calculating the cost of workrelated stress and psychosocial risks. European Risk Observatory Literature Review, [online] Available at: <https://osha.europa.eu/pl/tools-and-publications/publications/ literature_reviews/calculating-the-cost-of-work-related-stress-and-psychosocial-risks > [Accessed 2 June 2019].

Falco, A., Kravina, L., Girardi, D., Dal Corso, L., Di Sipio, A. and De Carlo, N.A., 2012. The convergence between self and observer ratings of workaholism: A comparison between couples. TPM: Testing, Psychometrics, Methodology in Applied Psychology, 19(4), pp.311-324.

Fry, L.W. and Cohen, M.P., 2009. Spiritual leadership as a paradigm for organizational transformation and recovery from extended work hours cultures. Journal of Business Ethics, 84(2), pp.265-278.

Gillet, N., Morin, A.J.S., Sandrin, E. and Houle, S.A., 2018. Investigating the combined effects of workaholism and work engagement: A substantive-methodological synergy of variable-centered and person-centered methodologies. Journal of Vocational Behavior, 109, pp.54-77.

Girardi, D., Falco, A., Piccirelli, A., Dal Corso, L., Bortolato, S. and De Carlo, A., 2015. Perfectionism and presenteeism among managers of a service organization: The mediating role of workaholism. TPM: Testing, Psychometrics, Methodology in Applied Psychology, 22(4), pp.507-521.

Grant, M.J. and Booth, A., 2009. A typology of reviews: An analysis of 14 review types and associated methodologies. Health Information and Libraries Journal, 26(2), pp.91-108. 
Griffiths, M.D., Demetrovics, Z. and Atroszko, P.A., 2018. Ten myths about work addiction. Journal of Behavioral Addictions, 7(4), pp.845-857. https://doi.org/ 10.1556/2006.7.2018.05.

Guglielmi, D., Simbula, S., Schaufeli, W.B. and Depolo, M., 2012. Self-efficacy and workaholism as initiators of the job demands-resources model. Career Development International, 17(4), pp.375-389.

Hancock, M.G., Balkin, R.S., Reiner, S.M., Williams, S., Hunter, Q., Powell, B. and Juhnke, G.A., 2019. Life balance and work addiction among NCAA administrators and coaches. The Career Development Quarterly, 67(3), pp.264-270.

Henry, S., 1979. Alcohol and drugs: The doctor's own prescription. Canadian Medical Association Journal, 120(8), pp.989-996.

Hey, S., 1994. Sick doctors. Workaholics harm families also. BMJ, 309(6963), p. 1235.

Imo, U.O., 2017. Burn-out and psychiatric morbidity among doctors in the UK: A systematic literature review of prevalence and associated factors. BJPsych Bulletin, 41(4), pp.197-204.

Jena, A.B., Baldwin, D.C., Daugherty, S.R., Meltzer, D.O. and Arora, V.M., 2010. Presenteeism among resident physicians. JAMA, 304(11), pp.1166-1168.

Jena, A.B., Meltzer, D.O., Press, V.G. and Arora, V.M., 2012. Why physicians work when sick. Archives of Internal Medicine, 172(14), pp.1107-1108.

Johns, G., 2010. Presenteeism in the workplace: A review and research agenda. Journal of Organizational Behavior, 31(4), pp.519-542.

Johnstone, A. and Johnston, L., 2005. The relationship between organizational climate, occupational type, and workaholism. New Zealand Journal of Psychology, 34, pp.181-188.

Judge, T.A., Piccolo, R.F. and Kosalka, T., 2009. The bright and dark sides of leader traits: A review and theoretical extension of the leader trait paradigm. The Leadership Quarterly, 20(6), pp.855-875.

Killinger, B., 1992. Workaholics: The respectable addicts. New York, NY: Fireside.

Kun, B., 2018. Ten myths and twenty years: What we know and what we still do not know about work addiction: Commentary on: Ten myths about work addiction (Griffiths et al., 2018). Journal of Behavioral Addictions, 7(4), pp.863-866. DOI: 10.1556/2006.7.2018.125.

Laxman, K.E., Lovibond, K.S. and Hassan, M.K., 2008. Impact of bipolar disorder in employed populations. The American Journal of Managed Care, 14(11), pp.757-764.

Lee, E.S., Park, T.Y. and Koo, B., 2015. Identifying organizational identification as a basis for attitudes and behaviors: A meta-analytic review. Psychological Bulletin, 141(5), pp.1049-1080.

Levecque, K., Anseel, F., De Beuckelaer, A., Van der Heyden, J. and Gisle, L., 2017. Work organization and mental health problems in $\mathrm{PhD}$ students. Research Policy, 46(4), pp.868-879.

Lichtenstein, M.B., Malkenes, M., Sibbersen, C. and Hinze, C.J., 2019. Work addiction is associated with increased stress and reduced quality of life: Validation of the Bergen Work Addiction Scale in Danish. Scandinavian Journal of Psychology, 60(2), pp.145-151. 
Lior, O., Abira, R. and Weinstein, A., 2018. Work addiction: An organizational behavior as well as an addictive behavior? Commentary on: Ten myths about work addiction (Griffiths et al., 2018). Journal of Behavioral Addictions, 7(4), pp.888-891.

Littman-Ovadia, H., Balducci, C. and Ben-Moshe, T., 2014. Psychometric properties of the Hebrew version of the Dutch Work Addiction Scale (DUWAS-10). The Journal of Psychology, 148(3), pp.327-346.

Loscalzo, Y. and Giannini, M., 2018. Problematic overstudying: Studyholism or study addiction? Commentary on: Ten myths about work addiction (Griffiths et al., 2018). Journal of Behavioral Addictions, 7(4), pp.867-870.

Machlowitz, M., 1980. Workaholics, living with them, working with them. Reading, MA: Addison-Wesley Publishing Company.

Malinowska, D., 2018. How to counter the ten myths about work addiction? Three postulates for future research: Commentary on: Ten myths about work addiction (Griffiths et al., 2018). Journal of Behavioral Addictions, 7(4), pp.871-874.

Marmet, S., Studer, J., Lemoine, M., Grazioli, V.S., Bertholet, N. and Gmel, G., 2019. Reconsidering the associations between self-reported alcohol use disorder and mental health problems in the light of co-occurring addictions in young Swiss men. Plos One, 14(9), p. e0222806.

Mazzetti, G., Schaufeli, W.B. and Guglielmi, D., 2014. Are workaholics born or made? Relations of workaholism with person characteristics and overwork climate. International Journal of Stress Management, 21(3), p. 227.

Mazzetti, G., Schaufeli, W.B. and Guglielmi, D., 2018. Are workaholism and work engagement in the eye of the beholder? A multirater perspective on different forms of working hard. European Journal of Psychological Assessment, 34(1), pp.30-40.

Mazzetti, G., Vignoli, M., Schaufeli, W.B. and Guglielmi, D., 2019. Work addiction and presenteeism: The buffering role of managerial support. International Journal of Psychology, 54(2), pp.174-179.

Midje, H.H., Nafstad, I.T., Syse, J. and Torp, S., 2014. Workaholism and mental health problems among municipal middle managers in Norway. Journal of Occupational and Environmental Medicine, 56(10), pp.1042-1051.

Molino, M., Bakker, A.B. and Ghislieri, C., 2016. The role of workaholism in the job demands-resources model. Anxiety, Stress, \& Coping, 29(4), pp.400-414.

Nature, Editorial, 2019. The mental health of $\mathrm{PhD}$ researchers demands urgent attention. Nature, 575, pp.257-258.

O'Boyle, E.H., Jr., Forsyth, D.R., Banks, G.C. and McDaniel, M.A., 2012. A meta-analysis of the Dark Triad and work behavior: a social exchange perspective. Journal of Applied Psychology, 97(3), pp.557-579.

Orosz, G., Dombi, E., Andreassen, C.S., Griffiths, M.D. and Demetrovics, Z., 2016. Analyzing models of work addiction: Single factor and bi-factor models of the Bergen Work Addiction Scale. International Journal of Mental Health and Addiction, 14(5), pp.662-671.

Panagioti, M., Panagopoulou, E., Bower, P., et al., 2017. Controlled interventions to reduce burn-out in physicians: A systematic review and meta-analysis. JAMA Internal Medicine, 177(2), pp.195-205. 
Price, R.K., Risk, N.K., Murray, K.S., Virgo, K.S. and Spitznagel, E.L., 2001. Twenty-five year mortality of US servicemen deployed in Vietnam: Predictive utility of early drug use. Drug and Alcohol Dependence, 64(3), pp.309-318.

Quinones, C., 2018. Moving from the terminology debate to a transdisciplinary understanding of the problem: Commentary on: Ten myths about work addiction (Griffiths et al., 2018). Journal of Behavioral Addictions, 7(4), pp.880-883.

Raiskila, T., Sequeiros, S. B., Kiuttu, J., Kauhanen, M. L., Läksy, K., Rissanen, P. ... and Joukamaa, M., 2013. Obsessive-compulsive personality disorder is common among occupational health care clients with depression. Journal of Occupational and Environmental Medicine, 55(2), pp.168-171.

Reiner, S.M., Balkin, R.S., Gotham, K.R., Hunter, Q., Juhnke, G.A. and Davis, R.J., 2019. Assessing life balance and work addiction in high- pressure, high- demand careers. Journal of Counselling \& Development, 97(4), pp.409-416.

Robertson, I.T. and Flint- Taylor, J., 2009. Leadership, psychological well- being, and organizational outcomes. In: S. Cartwright \& C.L. Cooper (Eds.), The Oxford handbook of organizational well-being, pp.159-179. Oxford, UK: Oxford University Press.

Rose, G., 2001 Sick individuals and sick populations. International Journal of Epidemiology, 30(3), pp.427-432.

Satel, S. and Lilienfeld, S.O., 2013. Addiction and the brain disease fallacy. Frontiers in Psychiatry, 4, p.141.

Scafuri Kovalchuk, L., Buono, C., Ingusci, E., Maiorano, F., De Carlo, E., Madaro, A. and Spagnoli, P., 2019. Can work engagement be a resource for reducing workaholism's undesirable outcomes? A multiple mediating model including moderated mediation analysis. International Journal of Environmental Research and Public Health, 16(8), p.1402.

Schaef, A.W. and Fassel, D., 1988. The addictive organization. New York, NY: Harper \& Row Publishers.

Schaufeli, W.B., Taris, T.W. and Bakker, A.B., 2006. Doctor Jekyll or Mr Hyde? On the differences between work engagement and workaholism. In: R.J. Burke (Ed.). Research companion to working time and work addiction, pp.193-217. Cheltenham Northampton, UK: Edward Elgar.

Shkoler, O., Rabenu, E., Vasiliu, C., Sharoni, G. and Tziner, A., 2017. Organizing the confusion surrounding workaholism: New structure, measure, and validation. Frontiers in Psychology, 8, p.1803.

Sinha, R., 2009. Stress and addiction: A dynamic interplay of genes, environment, and drug intake. Biological Psychiatry, 66(2), pp.100-101.

Snir, R. and Harpaz, I., 2006. The workaholism phenomenon: A cross-national perspective. Career Development International, 11(5), pp.374-393.

Snir, R., Harpaz, I. and Burke, R., 2006. Workaholism in organizations: New research directions. Career Development International, 11(5), pp.369-373.

Spagnoli, P., Balducci, C., Fabbri, M., Molinaro, D. and Barbato, G., 2019. Workaholism, intensive smartphone use, and the sleep-wake cycle: A multiple mediation analysis. International Journal of Environmental Research and Public Health, 16(19), p.3517. 
Spagnoli, P., Balducci, C., Scafuri Kovalchuk, L., Maiorano, F. and Buono, C., 2018. Are engaged workaholics protected against job-related negative affect and anxiety before sleep? A study of the moderating role of gender. International Journal of Environmental Research and Public Health, 15(9), p.1996.

Spence, J.T. and Robbins, A.S., 1992. Workaholism: Definition, measurement, and preliminary results. Journal of Personality Assessment, 58(1), pp.160-178. https://doi.org/10.1207/s15327752jpa5801_15.

Sussman, S., 2012. Workaholism: A review. Journal of Addiction Research \& Therapy, S6(1), pp.1-10. DOI: 10.4172/2155-6105.S6-001.

Sussman, S., 2018. Ten myths (or facts?) about workaholism: An appetitive motivation framework: Commentary on: Ten myths about work addiction (Griffiths et al., 2018). Journal of Behavioral Addictions, 7(4), pp.884-887.

Sussman S., Lisha N. and Griffiths M., 2011. Prevalence of the addictions: A problem of the majority or the minority? Evaluation \& the Health Professions, 34(1), pp.3-56.

Tariq, H., Weng, Q.D., Garavan, T. N., Obaid, A. and Hassan, W., 2019. Another sleepless night: Does a leader's poor sleep lead to subordinate's poor sleep? A spill-over/crossover perspective. Journal of Sleep Research, 29(1), p. e12904.

Tariq, H., Weng, Q. (Derek), Ilies, R. and Khan, A.K., 2019. Supervisory abuse of high performers: A social comparison perspective. Applied Psychology, p.12229.

Taris, T.W., Van Beek, I. and Schaufeli, W.B., 2012. Demographic and occupational correlates of workaholism. Psychological Reports, 110(2), pp.547-554.

Tóth-Király, I., Bőthe, B. and Orosz, G., 2018. Seeing the forest through different trees: A social psychological perspective of work addiction: Commentary on: Ten myths about work addiction (Griffiths et al., 2018). Journal of Behavioral Addictions, 7(4), pp.875-879.

Vincent, M.O., 1976. Are you hooked, doctor? Addiction among physicians. Canadian Family Physician, 22, pp.59-62.

Virtanen, M., Heikkilä, K., Jokela, M., et al., 2012. Long working hours and coronary heart disease: A systematic review and meta-analysis. American Journal of Epidemiology, 176(7), pp.586-596.

Wakefield, J.C. and Schmitz, M.F., 2013. When does depression become a disorder? Using recurrence rates to evaluate the validity of proposed changes in major depression diagnostic thresholds. World Psychiatry, 12(1), pp.44-52.

World Health Organization, 2019a. Burn-out an "occupational phenomenon": International Classification of Diseases, [online] Available at: <https://wwwwhoint/mental_health/ evidence/burn-out/en/> [Accessed 2 June 2019].

World Health Organization, 2019b. Mental health in the workplace, [online] Available at: <https://www.whoint/mental_health/in_the_workplace/en/> [Accessed 2 June 2019].

World Health Organisation, 2019c. International statistical classification of diseases and related health problems, $11^{\text {th }}$ Revision, Beta Draft, [online] Available at: <https://icd.who.int./browse11/1-m/en> [Accessed 2 June 2020].

Zimmerman, J.R., 2018. The meditational effects of employee engagement on the relationship between relational quality with supervisors and employee burnout. Doctoral dissertation. Available from ProQuest Dissertations \& Theses Global database. (UMI No. 10744383). 